\title{
Environmental pollution by persistent toxic substances and health risk in an industrial area of China
}

\author{
Jing $\mathrm{Li}^{1,2}$, Yonglong $\mathrm{Lu}^{1, *}$, Yajuan $\mathrm{Shi}^{1}$, Tieyu Wang ${ }^{1}$, Guang Wang ${ }^{1,2}$, \\ Wei Luo ${ }^{1}$, Wentao Jiao ${ }^{1}$, Chunli Chen ${ }^{1,2}$, Feng Yan ${ }^{1,2}$ \\ 1. State Key Laboratory of Urban and Regional Ecology, Research Center for Eco-Environmental Sciences, \\ Chinese Academy of Sciences, Beijing 100085, China.E-mail: lijing_cadx@163.com \\ 2. Graduate School of Chinese Academy of Sciences, Beijing 100039, China
}

Received 06 September 2010; revised 22 October 2010; accepted 18 November 2010

\begin{abstract}
Soil is an important environmental medium that is closely associated with humans and their health. Despite this, very few studies have measured toxicants in soils, and associated them with health risks in humans. An assessment of health effects from exposure to contaminants in soils surrounding industrial areas of chemical production and storage is important. This article aims at determining pollution characteristics of persistent toxic substances (PTS) in an industrial area in China to unravel the relationship between soil pollution by PTS and human health. One hundred and five soil samples were collected and 742 questionnaires were handed out to residents living in and around an industrial area around Bohai Bay, Tianjin in Northern China. Concentrations of organochlorine pesticides and polycyclic aromatic hydrocarbons (PAHs) were determined in soil. Mann-Whitney U and binary multivariate nonconditional logistic regression models were employed to analyze the relationship between health indicators of local residents and contaminant levels. Odds ratio (OR) and a 95\% confidence interval (CI) for health incidences were also calculated. The average concentrations of DDT $(73.9 \mathrm{ng} / \mathrm{g}), \mathrm{HCH}(654 \mathrm{ng} / \mathrm{g})$ and PAHs $(1225 \mathrm{ng} / \mathrm{g})$ were relatively high in the industrial area. Residents living in the chemical industry parks were exposed to a higher levels of PTS than those living outside the chemical industry parks. This exposure was associated with a higher risk of breast cancer (OR 1.87, 95\% CI 0.12-30.06), stomach cancer (OR 1.87, 95\% CI 0.2613.41), dermatitis (OR 1.72, 95\% CI 1.05-2.80), gastroenteritis (OR 1.59, 95\% CI 0.94-2.68), and pneumonia (OR 1.05, 95\% CI $0.58-1.89)$.
\end{abstract}

Key words: organochlorine pesticides; polycyclic aromatic hydrocarbons; soil pollution; questionnaire survey; health risk DOI: $10.1016 /$ S1001-0742(10)60554-2

Citation: Li J, Lu Y L, Shi Y J, Wang T Y, Wang G A, Luo W et al., 2011. Environmental pollution by persistent toxic substances and health risk in an industrial area of China. Journal of Environmental Sciences, 23(8): 1359-1367

\section{Introduction}

Because of their persistence, bioaccumulation, toxicity, and long-range environmental transport ability, persistent toxic substances (PTSs) are of concern to both scientists (Dewailly et al., 2006; Tao et al., 2006) and environmental quality managers or policy makers (Wang et al., 2005). PTSs pose critical public health problems that impact survival and cause adverse health outcomes in the twentyfirst century. Several of the PTSs are associated with human diseases including breast cancer and reduced semen quality (Kannan et al., 1997). Twelve persistent organic pollutants (POPs) defined by the Stockholm Convention and the twelve persistent bioaccumulative and toxic chemicals (PBTs) designated by the US EPA environmental endocrine disruptors (EEDs) are all PTS. PTSs, as defined by the united nation environmental programme (UN-

\footnotetext{
* Corresponding author. E-mail: yllu@ @rcees.ac.cn
}

EP), contain twenty-seven chemical pollutants, such as organochlorine pesticides (OCPs) and polycyclic aromatic hydrocarbons (PAHs).

In China, OCPs (such as DDT, HCH, and HCB) and PAHs are the most frequently studied PTSs in soil, such that more than 600 soil samples collected from various cities and regions have been analyzed for the occurrence of PAHs and OCPs (Cai et al., 2008). Concentrations of PAHs in soil have been increasing during the past 100 150 years, especially in urban areas. However, relatively few studies have investigated the potential of these toxic residues to affect the health of humans. There are a number of locations in China where OCPs are manufactured, stored or disposed. Even though production at many of these sites has ceased, residual contamination still may present hazards to humans, especially when these sites are converted for other uses (Wang et al., 2009). In China, very few assessments of the potential health effects of these sites on human health have been conducted. 
Human exposure to PTS is ubiquitous and is not restricted to individuals who live near industrial areas or waste disposal sites. Soils can significantly influence human exposure to toxicants and consequently cause health risks. Through ingestion, either deliberately or involuntarily, inhalation, and dermal absorption, the mineral, chemical and biological components of soils can either be directly beneficial or detrimental to human health (Cai et al., 2008; US EPA, 2002). Human health can also be influenced indirectly as soils interact with the atmosphere, biosphere, and hydrosphere. Potentially harmful elements from soils can be transferred to the plants and animals that constitute the human food chain (Smith and Lee, 2003). The volatilization of POPs from soils and their subsequent global redistribution has impacted the health of people, even those living in remote areas such as Arctic (Dewailly et al., 2006). However, the relationship between human health outcomes and soil contamination by PTS has still been under-appreciated and under-reported (Abrahams, 2002).

While the relationship between PTS exposure and adverse health effects on humans is not yet unequivocally established, PTS exposures have been demonstrated to alter cellular homeostasis. Several epidemiologic studies have shown that PTS including PAHs and OCPs can be absorbed by human body through the skin, lungs, and alimentary canals, and can induce skin cancer, lung cancer, stomach cancer, breast cancer, uterine myoma, prostate cancer, and scrotum cancer (Jane et al., 2000). Occupational exposure to DDT is associated with increased lung cancer in a case control study of Uruguayan work force (Destefani et al., 1996). According to the International Agency for Research on Cancer (IARC,1987), soot and tar, untreated and mildly treated mineral oils, and processes used in the production of aluminum and coke or in iron and steel foundries are carcinogenic in humans. Because PAHs are common in these exposures, it is believed that PAH exposure can result in cancers. For example, the high lung cancer rate in Xuanwei County, China, is associated with the use of coal in unvented houses, but not with wood or smokeless coal (Mumford et al., 1995). Combustion of coal that releases smoke emits higher PAH concentrations than does wood combustion. Research in 1892 revealed that workers dealing with coal tar and pitch were more likely to have skin cancer than workers in other sectors (IARC, 1987). Chimney cleaners tended to have a higher chance of having scrotum cancer (Gerber et al., 1995). A high lung cancer mortality rate was found among Icelanders who frequently ate smoked food (Gelboin and Paul, 1979).

This article presents the results of a case study on the Tianjin Binhai New Area (BHNA). It addresses five questions: (1) the current pollution status of PTS in the newly developing industrial area; (2) the occurrence of potential pollution sources; (3) the health conditions of local residents; (4) the impact on human health by PTS pollution in a chemical industrial park; and (5) the association between soil residues of pollutants and health of residents. Two types of persistent and ubiquitous pollutants were examined in this study: PAHs and OCPs. These were both used as soil contamination indicators at BHNA (MotelayMassei et al., 2004). Initially, concentrations of 16 priority PAHs, identified by the US EPA, and OCPs (including DDTs, HCHs, and HCB) were detected in 105 soil samples collected in the BHNA. The concentrations of PTSs inside chemical industry parks were compared to those outside of chemical industry parks. Then, based on the concentrations of 105 sample sites and comparisons to China's National Environmental Quality Standards, 742 questionnaires were sent to twenty-three sites in the study area to investigate the residents' health. The relationship between soil pollution by PTS and human health in the industrial area was analyzed by Mann-Whitney $U$ and binary multivariate nonconditional logistic regression models.

\section{Materials and methods}

\subsection{Description of study area}

The BHNA $\left(38^{\circ} 40^{\prime} \mathrm{N}-39^{\circ} 00^{\prime} \mathrm{N}\right.$ and $117^{\circ} 20^{\prime} \mathrm{E}-$ $\left.118^{\circ} 00^{\prime} \mathrm{E}\right)$ is located at the intersection of the Beijing-Tianjin-Hebei Economic Zone and the center of the Bohai Bay Rim City belt, in northern China, approximately $100 \mathrm{~km}$ northeast to Beijing. The total area of the BHNA is approximately $2270 \mathrm{~km}^{2}$, in three administrative districts, Hangu, Tanggu, and Dagang from north to south (Fig. 1).

With rapid industrialization and general economic development, historical chemical industrial parks have become an issue. Three of these areas in the BHNA were investigated for their potential effects on humans. The three

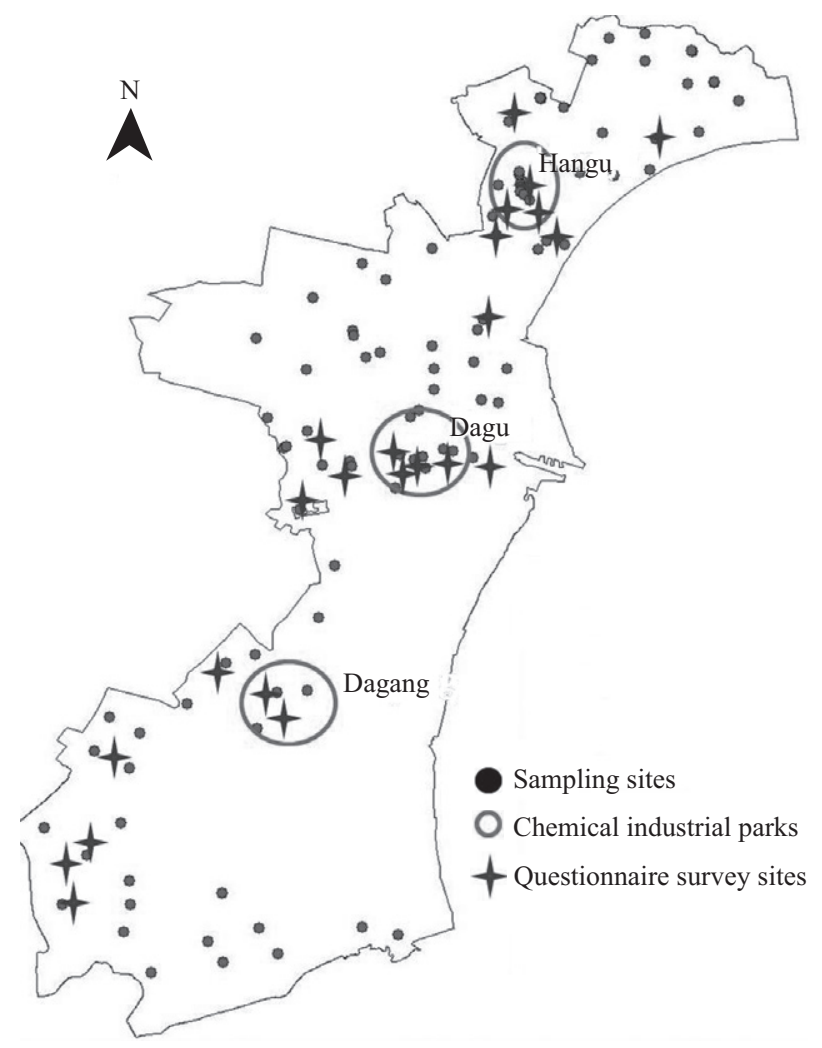

Fig. 1 Map of regional site, sampling sites and social survey sites. 
sites are the Hangu Chemical Industrial Park, the Dagu Chemical Industrial Park, and the Dagang Oil-refinery Region, located in the Hangu, Tanggu, and Dagang districts, respectively. There has been a long history of pollution and complex sources of contamination at the BHNA. The Tianjin Chemical Company and Dagu Chemical Company, located within the Hangu and Dagu Chemical Parks, separately, were once among the largest producers of OCPs in China. Large amounts of lindane, dicofol, and technical $\mathrm{HCH}$ as well as most of $\mathrm{HCB}$ and technical DDT were produced in those parks (Tao et al., 2006). In addition, some other manufacturers in the BHNA have produced dicofol since 1990 (Hu et al., 2005). The Tianjin Soda Plant, established in 1917, was well known as the cradle of the Chinese soda industry and is the base for the modern chemical industry in China. The Tianjin Chemical Plant was a large-scale chlor-alkali enterprise founded in 1938. Furthermore, in the national development plan for oil refineries and ethylene production, Tianjin was identified as the national petrochemical industry base, with a planning capacity of 2-3 sets of million-ton ethylene, and 10 million-ton refining oil. At the same time, many old factories in the regions rely on coal for energy, and thus these facilities were also the sources of PAHs.

These sites are characterized by contaminated areas where OCPs had been stored or waste products had been dumped. In particular, the sites are contaminated with technical mixtures of DDT and HCB. Because of the persistence and the bioaccumulative potential of OCPs, the potential chronic carcinogenic effects on humans living around these industrial parks need investigation.

Besides large proportion of industrial areas, there are also parts of agricultural areas and many undeveloped barren lands in the BHNA. Wheat, maize, cotton, jujube and grapes are the main crops across the study area.

\subsection{Soil sampling and analytical method}

One hundred and five surface soil samples were collected. The sampling locations covered the entire area, with a relatively uniform distribution $(7 \mathrm{~km} \times 7 \mathrm{~km})$. Thirty-two sampling sites were collected inside the chemical industry parks and 73 were outside. Each sample was mixed from five sub-samples collected from five locations in an area of about $100 \mathrm{~m} \times 100 \mathrm{~m}$ (at four corners and the center). All soil samples were collected at a depth of 0-20 cm using a stainless steel shovel. Grass, pebbles, and other sundries were removed from the surface of each location before the sample was collected.

The soil samples were air-dried at room temperature (Nadal et al., 2004), sieved to $<2 \mathrm{~mm}$, and stored at $4^{\circ} \mathrm{C}$. Site descriptions such as land use type and major environmental features were recorded. Concentrations of typical PTSs including DDTs, HCHs, HCB, and PAHs were determined in our laboratory. PAHs were extracted by a Soxhlet apparatus, and quantified by use of an Agilent 6890 GC equipped with a 5973 mass selective detector (MSD) under the selected ion-monitoring mode (SIM). The OCPs were extracted with hexane/dichloromethane $(1: 1, V / V)$ by ultrasonication, and analyzed by using GC- $\mu E C D$ under the splitless mode. The details of the methods for sample extraction and analysis have been described elsewhere (Li et al., 2008a; Wang et al., 2009).

\subsection{Recruitment and survey of residents}

A survey questionnaire was administered for selfreporting of the health status of individuals living in the BHNA; such surveys have been shown to be useful for obtaining health outcome information and appropriate to identify the health of residents (Husain et al., 2006; Scazufca et al., 2009). Based on the concentrations of PTS in 105 sample sites, we identified 23 social survey sites and distributed 742 questionnaires to local residents. Uniformly designed questionnaires were used for the survey and the data were collected by trained investigators. The questionnaire was pre-tested among 10 randomly selected individuals met at the largest market in the BHNA. It was then modified for clarity and context. A random sample survey methodology was employed. Twenty-five to thirty-five individuals were chosen randomly in each site within a three-block radius to ensure coverage of the study area. In this study, people living inside and outside of chemical industrial parks of the BHNA were used as the cases and controls, respectively. All the people interviewed expressed enthusiasm in providing information on their health status, and promised to answer the questions objectively after knowing that we were carrying out scientific research. These twenty-three sites are shown in Fig. 1. Because every interview was conducted face to face, all of the 742 questionnaires were available. For each interview, three kinds of information were collected. The first kind was individual's background information including gender, age, career, education, type of inhabitation, and pollution sources around their home; the second kind included the individual's health statement, containing family-history and statement of his/her health situation in terms of normal and rare diseases; and the third kind included his/her dietary structure, smoking habits, and duration of daily outdoor activity. Those who had lived in the area for less than five years were not included in this survey. Data reliability was ensured through double entry verification. Survey data were entered into MS Excel for further analysis.

\subsection{Statistical analysis}

SPSS 12.0 for Windows was used for statistical analysis. Since the data were not normally distributed, non-parametric Mann-Whitney U and Kruskal-Wallis tests were used to identify differences in health conditions of the people living inside and outside the chemical industrial. To analyze the relationship between the health status of the residents and potential confounding factors, binary multivariate non-conditional logistic regression analysis and spearman's correlation analysis were employed. Then prevalence estimates of odds ratios (OR) and 95\% confidence intervals (CI) were presented, which were calculated from the regression analyses taking into account of relative risk. 


\section{Results and discussion}

\subsection{Concentrations of OCPs and PAHs in the BHNA}

OCPs were detected in $99 \%$ of the surface soil samples in the BHNA, and the compositions of residue levels are shown in Table 1. Quartiles (the 25th, 50th, and 75th percentiles) divide the ordered data into four groups of equal size. The 50th quartile is the median value.

The total concentrations of DDTs (including $p, p /$-DDT, $p, p$-DDE, $p, p$-DDD, $o, p$-DDT) varied from ND (less than the limit of quantification) to $2417 \mathrm{ng} / \mathrm{g}$ (with a mean value of $73.9 \mathrm{ng} / \mathrm{g}$ ). As shown in Fig. 2a, these levels were similar to those in Beijing surface soils (77 ng/g) (Zhang et al., 2006a), and higher than others that were reported earlier in China, such as the levels in Nanjing industrial soils (31 ng/g) (An et al., 2005), Nanjing agricultural soils (11 ng/g) (Ge et al., 2006), Huang-Huai-Hai Plain (11 $\mathrm{ng} / \mathrm{g}$ ) (Zhao et al., 2005), Hong Kong surface soils (0.52 ng/g) (Zhang et al., 2006b), and Pearl River Delta surface soils (35 ng/g) (Li et al., 2006), but much lower than levels found in the urban and industrial soils of Poland (260 ng/g) (Falandysz et al., 2001), which were very close to an industrial area.

$\mathrm{HCH}$ residues (including $\alpha, \beta, \gamma, \delta$-isomers) were detected in $97.1 \%$ of soil samples, and the total concentrations varied from ND to $51,299 \mathrm{ng} / \mathrm{g}$ (with a mean value of $653.6 \mathrm{ng} / \mathrm{g}$ ). This was significantly higher than the levels reported earlier (Fig. 2b), which indicated that the soils at the BHNA were heavily contaminated by $\mathrm{HCH}$.

The total concentrations of HCB varied from ND to $731 \mathrm{ng} / \mathrm{g}$ (with a mean value of $7.7 \mathrm{ng} / \mathrm{g}$ ). If the sample with highest concentration was excluded, the mean concentration of $\mathrm{HCB}$ would only be $(0.67 \pm 1.75) \mathrm{ng} / \mathrm{g}$, which was lower than that found in Nanjing industrial soils (20 $\mathrm{ng} / \mathrm{g}$ ) (An et al., 2005), and central Germany (0.57-3.75 $\mathrm{ng} / \mathrm{g}$ ) (Manz et al., 2001). In addition, HCBs residues were detected only in $23.8 \%$ of soil samples, which indicated that there is no extensive HCB soil pollution at the BHNA.
PAHs were detected in $100 \%$ of the surface soil samples at the BHNA, and the residue levels are shown in Table 1. The total concentrations of PAHs varied from 68.7 to $43,930 \mathrm{ng} / \mathrm{g}$, with a mean value of $1225 \mathrm{ng} / \mathrm{g}$. This was higher than that in some developed regions in China (Fig. 2c), such as in the Shantou economic development zone (317 ng/g) (Hao et al., 2004), Hong Kong (443 ng/g) (Chung et al., 2007), and the Xuzhou urban area $(27 \mathrm{ng} / \mathrm{g}$ ) (Ge et al., 2008), while lower than that in Beijing urban soils (1637 ng/g) (Li et al., 2006), Dalian surface soils (1738 ng/g) (Wang et al., 2007), France surface soils (2510 $\mathrm{ng} / \mathrm{g}$ ) (Motelay-Massei et al., 2004), and the soils of a suburban district in the USA (527-3753 ng/g) (Mielke et al., 2004). Furthermore, according to the standard proposed by Maliszewska-Kordybach (1996), only $7.6 \%$ of the soil samples can be considered unpolluted (<200 ng/g), $45.7 \%$ as slightly polluted (200-600 ng/g), $22.9 \%$ as moderately polluted (600-1000 ng/g), and $23.8 \%$ as severely polluted by PAHs (> $1000 \mathrm{ng} / \mathrm{g})$.

\subsection{Environmental pollution in chemical industry parks}

The three chemical industrial parks are centers of exposure of local residents. The results showed that the total concentration of DDT in the Dagu chemical industrial park (mean value $442.6 \mathrm{ng} / \mathrm{g}$ ) was significantly higher than that identified in Hangu $(16.4 \mathrm{ng} / \mathrm{g}$ ) and in Dagang chemical parks $(1.57 \mathrm{ng} / \mathrm{g})$, namely, 27 times higher in Dagu than in Hangu (Table 2). This was due to the production history of DDT in the Dagu chemical industrial park, suggesting that the Dagu chemical industrial park is a point source emission of the chemical industry for DDT. The concentrations of total $\mathrm{HCHs}$ and total $\mathrm{HCB}$ in surface soils in Hangu (387.4 and $0.74 \mathrm{ng} / \mathrm{g}$ ) were relatively higher than those in Dagu chemical industrial parks (333.6 and 0.35 $\mathrm{ng} / \mathrm{g}$ ), and the concentrations of HCHs in the Dagang oilproduction region $(77.9 \mathrm{ng} / \mathrm{g}$ ) were just one-fifth of those in Hangu. Moreover, HCB was not detected in Dagang

Table 1 Residue levels (ng/g) of compositions of PAHs and OCPs in soil samples from the BHNA

\begin{tabular}{|c|c|c|c|c|c|c|c|c|c|c|}
\hline Quartiles & Nap & Any & Ane & Fle & Phe & Ant & Fla & Pyr & $\mathrm{Baa}$ & $\mathrm{Chr}$ \\
\hline 25 th & 66.8 & 0 & 0 & 3.6 & 37.4 & 2.5 & 18.8 & 12.3 & 2.4 & 13.7 \\
\hline 50th & 122 & 0 & 0 & 16.8 & 49 & 21.5 & 41.2 & 30.3 & 9.5 & 32.5 \\
\hline 75 th & 179.2 & 0 & 0 & 31.3 & 75.3 & 52.7 & 68.9 & 54 & 28.7 & 81 \\
\hline $\mathrm{DR}^{\mathrm{a}}$ & 89.4 & 0 & 9.6 & 89.4 & 95.2 & 80.8 & 99 & 100 & 77.9 & 100 \\
\hline Quartiles & $\mathrm{Bbf}$ & $\mathrm{Bkf}$ & Bap & Ilp & Daa & Bgp & $\sum$ PAHs & $\sum$ PAHscar $^{\mathrm{b}}$ & $\alpha-\mathrm{HCH}$ & $\beta-\mathrm{HCH}$ \\
\hline 25 th & 18.3 & 7.8 & 8.1 & 10.5 & 0 & 12.3 & 319.8 & 72.8 & 0 & 1.7 \\
\hline 50th & 33.8 & 15.6 & 21 & 25.1 & 0.7 & 21.7 & 553.7 & 176.5 & 0 & 2.7 \\
\hline 75 th & 84.4 & 48.9 & 98.2 & 104.6 & 54.1 & 128.2 & 978.4 & 529.2 & 1.1 & 4.2 \\
\hline $\mathrm{DR}^{\mathrm{a}}$ & 91.3 & 97.1 & 97.1 & 95.2 & 95.2 & 95.2 & 100 & 100 & 32.4 & 76.2 \\
\hline Quartiles & $\gamma-\mathrm{HCH}$ & ঠ-HCH & $\sum \mathrm{HCHs}$ & $p, p^{\prime-\mathrm{DDE}}$ & $p, p^{\prime-\mathrm{DDD}}$ & $o, p \prime-\mathrm{DDT}$ & $p, p^{\prime-D D T}$ & $\sum \mathrm{DDTs}$ & $\mathrm{HCB}$ & \\
\hline 25 th & 4.7 & 0 & 7.6 & 0 & 0 & 0 & 0 & 0.7 & 0 & \\
\hline 50th & 27.9 & 0 & 36 & 1.9 & 0 & 0 & 0 & 5.3 & 0 & \\
\hline 75th & 102.8 & 0 & 118.6 & 6.5 & 3.5 & 0 & 10 & 19.5 & 0 & \\
\hline $\mathrm{DR}^{\mathrm{a}}$ & 97.1 & 13.3 & 97.1 & 59 & 44.8 & 17.1 & 48.6 & 75.2 & 23.8 & \\
\hline
\end{tabular}

${ }^{\mathrm{a}}$ Detectable ratio; ${ }^{\mathrm{b}}$ carcinogenic PAH compound.

Nap: naphthalene; Any: acenaphthylene; Ane: acenaphthene; Fle: fluorene; Phe: phenanthrene; Ant: anthracene; Fla: fluoranthene; Pyr: pyrene; Baa: benz[a]anthracene; Chr: chrysene; Bbf: benzo[b]fluoranthene; Bkf: benzo[k]fluoranthene; Bap: benzo[a]pyrene; IlP: indeno[1,2,3-cd]pyrene; Daa: dibenz[a,h]anthracene; BgP: benzo[g,h,i]perylene. 

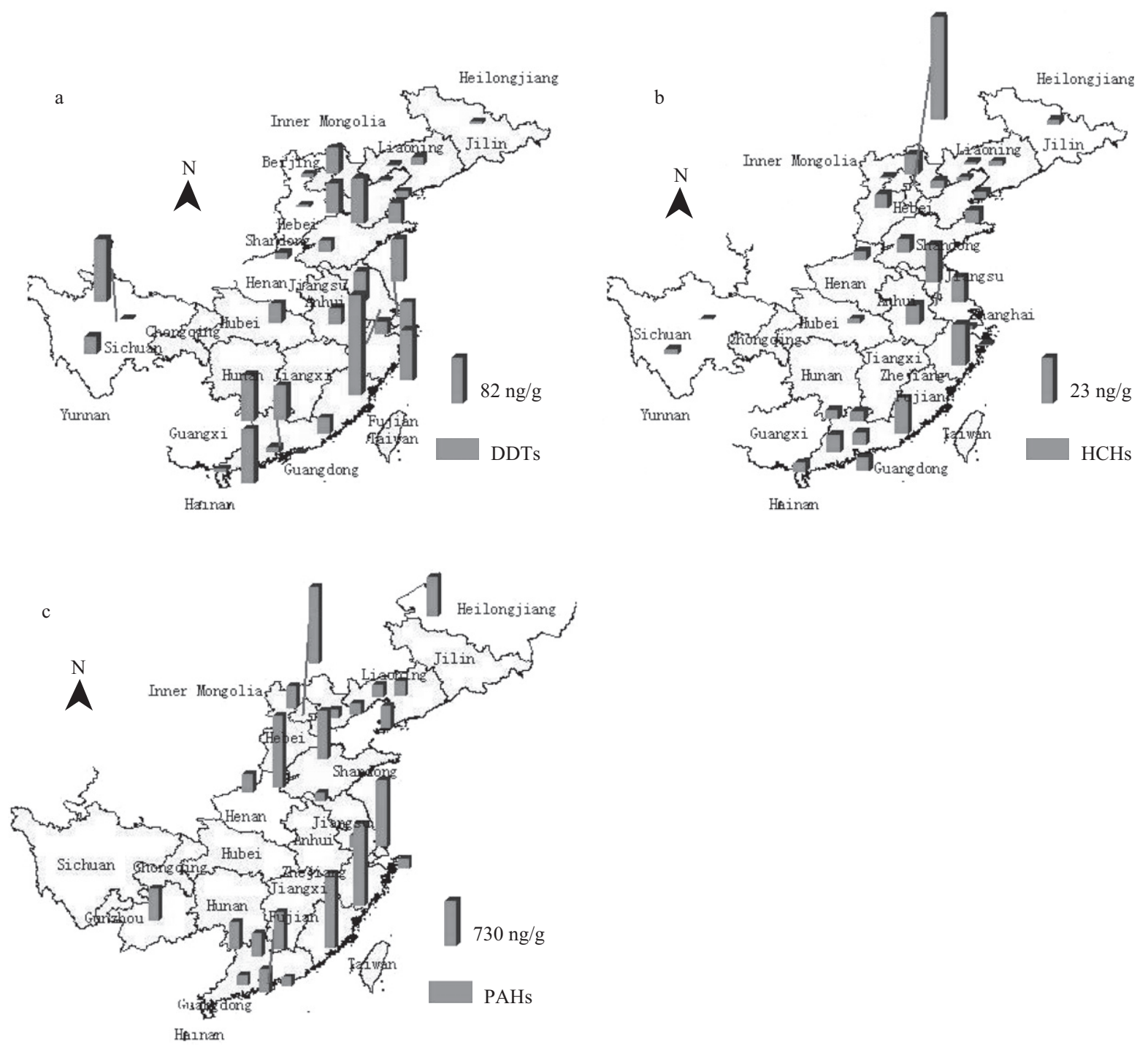

Fig. 2 Comparison of POPs in soils at the BHNA with other regions in China. (a) Data are from references of An et al., 2005; Ge et al., 2006; Gong et al., 2003a; Jin et al., 2009; Li et al., 2008a; Lin et al., 2009; Liu et al., 2008b; Ma and Ran, 2009; Pang et al., 2009; Wong et al., 2006; Zhang et al., 2006a, 2006b, 2009; Zhao, 2005; Zhou and Cui, 2009. (b) Data are from references of An et al., 2005; Ge et al., 2006; Gong et al., 2003b; Jin et al., 2009; Liu et al., 2008a, 2008b; Ma and Ran, 2009; Pang et al., 2009; Wong et al., 2006; Zhang et al., 2006a, 2006b, 2009; Zhao, 2005; Zhou and Cui, 2009. (c) Data are from references of Ge et al., 2006, 2008; Hu et al., 2006; Li et al., 2006; Liao, 2009; Liu et al., 2008; Lu et al., 2008; Ma and Ran, 2009; Shen and Zhu, 2007; Sun et al., 2007, 2008; Xiao et al., 2008.

Table 2 Differences in the concentrations (ng/g) of PTSs in soils from three chemical industry parks

\begin{tabular}{llllll}
\hline District & $\sum$ DDTs & $\sum$ HCHs & $\sum$ HCB & $\sum$ PAHs & $\sum$ PAHscar $^{\mathrm{a}}$ \\
\hline Hangu & 16.4 & 387.4 & 0.74 & 969.7 & 533.2 \\
Dagu & 442.6 & 333.6 & 0.35 & 2030 & 1030 \\
Dagang & 1.57 & 77.9 & ND & 904.8 & 414.2 \\
$\begin{array}{l}\text { Outsides } \\
\text { chemical }\end{array}$ & 18.5 & 140.1 & 0.6 & 712.5 & 293.6 \\
parks & & & & & \\
\hline
\end{tabular}

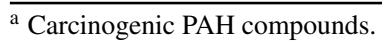

oil-production region. There was no production history of OCPs in Dagang oil-refinery region.

As for the concentrations of $\sum$ PAHs, of the three chemical industry parks, the Dagu chemical industrial park was ranked at the top $(2030 \mathrm{ng} / \mathrm{g})$, followed by the Hangu chemical industrial park $(969.7 \mathrm{ng} / \mathrm{g})$, and finally the Dagang oil-refinery region $(904.8 \mathrm{ng} / \mathrm{g})$, with a similar order for the $\sum$ PAHscar (1030, 533.2 and $414.2 \mathrm{ng} / \mathrm{g}$, respectively). The Dagu chemical industrial park has a number of large chemical enterprises that use coal as a primary fuel source and has a long production history, relatively obsolete equipment, and a lack of effective emission reduction measures against PAHs. The Hangu chemical industrial park was established in 1996, and, although its principal components were chemical industries, a series of technical measures for environmental protection were taken at the beginning of its development. These include wastewater treatment, centralized garbage/solid waste processing, and exhaust gas treatment. These may be the important reasons for the concentration difference in PAHs between the two chemical industry parks. The lowest concentrations of PAHs were in the Dagang oil-production region, showing that the impact of oil production on the surrounding soil content of PAHs was relatively low. 


\subsection{Human health effects survey}

All of the 742 questionnaires were collected from the twenty-three sites located around the BHNA. The demographic characteristics of the subjects are summarized as follows. The sample consisted of 393 (53\%) male and 349 $(47 \%)$ female participants. The average age was 44.6 years old, with $69.5 \%$ of the participants aged between 18 and 60 years old, and $22.3 \%$ above 60 years old. Two hundred and one residents $(27 \%)$ were living in chemical industrial parks and $541(73 \%)$ residents were from a reference location, away from the chemical industry parks. The Mann-Whitney U Test showed that there was a significant difference in residents' educational characteristics. More people living in and around chemical industry parks were reported to have a higher education than those living out of chemical parks $(73.6 \%$ versus $53.2 \%, P<0.01)$.

Recent epidemiological studies have reported evidence of the carcinogenic effects of PTS in occupationally exposed subjects. Cancers caused by the PTS include skin cancer, lung cancer, stomach cancer, breast cancer, uterine myoma, prostate cancer, and scrotum cancer (Gerber et al., 1995; Jane et al., 2000; Mumford et al., 1995). Chronic health outcomes, such as dermatitis, pneumonia, and gastroenteritis were also identified as local residents' health indicators to reflect human health after long-time exposure to PTS pollution. As for "possible" early symptoms listed to reflect human health after long exposure to PTS pollution, dermatitis was found to be a common disease in the BHNA, especially in residents living in chemical industrial parks during our pre-social survey. Dermatitis,

Table 3 Morbidities statistics of target diseases*

\begin{tabular}{lll}
\hline Disease & Overall $(\%)$ & Adjusted $\left(10^{-6}\right)$ \\
\hline Dermatitis & 13.2 & 720.5 \\
Skin cancer & 0.2 & 10.4 \\
Lung cancer & 0.7 & 29.5 \\
Pneumonia & 9.2 & 382.8 \\
Stomach cancer & 0.7 & 33 \\
Gastroenteritis & 11.3 & 546.9 \\
Breast cancer & 0.3 & 15.6 \\
Uterine myoma & 0.2 & 10.4 \\
Prostate cancer & 0.5 & 22.6 \\
Scrotum cancer & 0.2 & 8.7 \\
\hline
\end{tabular}

* Morbidities were adjusted by the world population standard published in 1985 by WHO. which is one of the early symptoms of skin cancer, can be induced by PTS, and was therefore chosen to be one of the indicators. The health status of residents living in the BHNA are described in Table 3.

The results show that morbidities from dermatitis (13.2\%), gastroenteritis $(11.3 \%)$ and pneumonia (9.2\%) ranked as the top three diseases in the BHNA area. Crude (overall) morbidities of target cancers were between $0.2 \%$ and $0.7 \%$. Among all the cancers, incidences of stomach cancer ranked at the top, followed by lung cancer. Although the crude morbidities from these two cancers were equal, the age-adjusted morbidity of stomach cancer is higher than that of lung cancer.

\subsection{Impacting factors on human health}

Except for lung cancer, morbidities from other cancers, such as from stomach cancer and breast cancer, and also from possible early symptoms corresponding to such cancers, such as dermatitis, pneumonia, and gastroenteritis, were all higher in individuals living inside the chemical industry parks than in those live outside the chemical parks (Table 4). Risks for breast cancer (OR 1.87, 95\% CI 0.12-30.06) and stomach cancer (OR 1.87, 95\% CI 0.2613.41) were higher than for other diseases, followed by dermatitis (OR 1.72, 95\% CI 1.05-2.80), gastroenteritis (OR 1.59, 95\% CI 0.94-2.68), and pneumonia (OR 1.05, 95\% CI 0.58-1.89). As regards to carcinogenic affects, epidemiologic evidences are clearly suggestive of cases with high pollution levels (IARC, 1987; Turusov et al., 2002). Mortality from stomach cancer showed a significant 2-fold excess among DDT-exposed workers in the highest quartile of cumulative exposure (Cocco et al., 2005). Although risks tended to increase with cumulative and average exposure, the trend was not significant (Cocco et al., 2005). The binary multivariate non-conditional logistic regression models showed that except for dermatitis, there was no significant difference between morbidities of all targeted diseases for residents living inside or outside the chemical parks. Interactions were considered to be significant at an alpha level of 0.05 on a two-tailed test, performed with the statistical software SPSS 12.0. However, the OR of lung cancer was 0.62 , which is less than 1. Skin cancer, prostate cancer, and scrotum cancer were not found in chemical industry parks, while uterine myoma

Table 4 Morbidity statistics differences in target diseases of local residents between those living inside and outside of chemical parks

\begin{tabular}{|c|c|c|c|c|c|c|c|c|}
\hline \multirow[t]{2}{*}{ Disease } & \multirow{2}{*}{$\begin{array}{l}\text { Chemical } \\
\text { parks }(\%)\end{array}$} & \multirow{2}{*}{$\begin{array}{l}\text { Adjusted } \\
\left(10^{-6}\right)\end{array}$} & \multirow{2}{*}{$\begin{array}{l}\text { Non-chemical } \\
\text { parks }(\%)\end{array}$} & \multirow{2}{*}{$\begin{array}{l}\text { Adjusted } \\
\left(10^{-6}\right)\end{array}$} & \multirow[t]{2}{*}{$X^{2}$} & \multirow[t]{2}{*}{ OR } & \multicolumn{2}{|c|}{$95 \% \mathrm{CI}$} \\
\hline & & & & & & & Lower & Upper \\
\hline Dermatitis & 17.4 & 925.4 & 10.9 & 610.7 & 0.02 & 1.72 & 1.05 & 2.80 \\
\hline Skin cancer & - & - & 0.3 & 16 & 0.65 & - & - & - \\
\hline Lung cancer & 0.5 & 19.9 & 0.8 & 34.7 & 0.57 & 0.62 & 0.06 & 6.00 \\
\hline Pneumonia & 9.5 & 430.3 & 9.1 & 453.3 & 0.49 & 1.05 & 0.58 & 1.89 \\
\hline Stomach cancer & 1 & 34.8 & 0.5 & 32 & 0.44 & 1.87 & 0.26 & 13.41 \\
\hline Gastroenteritis & 14.4 & 751.2 & 9.6 & 509.3 & 0.06 & 1.59 & 0.94 & 2.68 \\
\hline Breast cancer & 0.5 & 19.9 & 0.3 & 13.3 & 0.58 & 1.87 & 0.12 & 30.06 \\
\hline Uterine myoma & 0.5 & 29.9 & - & - & 0.35 & - & - & - \\
\hline Prostate cancer & - & - & 0.8 & 34.7 & 0.28 & - & - & - \\
\hline Scrotum cancer & - & - & 0.3 & 13.3 & 0.65 & - & - & - \\
\hline
\end{tabular}

-: not found. 
was not found in non-chemical parks.

Correlation between the concentrations of PTSs in soil and the health status of residents living in corresponding areas was analyzed by non-parametric Spearman's rho test, but the correlation coefficient was very low $(R<$ 0.2 ), and no significant statistical association was found. This agrees with the statement that cancer risks under conditions of exposure to moderate or low pollution levels are currently less clear and often contradictory, with some epidemiological studies showing a lack of association and others showing increased risks of up to approximately 1.5 times (Hemminki and Pershagen, 1994). It is possible that the residue levels of PTSs in this industrial area had not reached the level that would increase the risk of having cancer, and it is speculated that air particles, diet, etc., can be the primary means of PTS exposure to humans in the chemical industry park (Abrahams, 2002). The impact on human health from direct soil exposure is relatively low compared to inhalation and diet, especially around the chemical industrial parks.

\section{Conclusions}

The residue levels of PAHs and OCPs (HCHs, DDTs and $\mathrm{HCB}$ ) were investigated in soils from an industrial area in China. Concentrations of DDT, HCHs, and PAHs were higher than those reported in most of the earlier studies, revealing that this area is seriously contaminated. According to the National Environmental Quality Standards for Soils in China, the levels of OCPs were above that could cause long-term ecotoxicological damage. As for PAHs, only $7.6 \%$ of the soil samples can be considered unpolluted $(<$ $200 \mathrm{ng} / \mathrm{g}$ ), $45.7 \%$ slightly polluted (200-600 ng/g), $22.9 \%$ moderately polluted $(600-1000 \mathrm{ng} / \mathrm{g})$, and $23.8 \%$ severely polluted (> $1000 \mathrm{ng} / \mathrm{g})$.

Human populations living around the chemical industry parks are exposed to higher levels of PTS from soil than those living outside the chemical parks, and morbidities of most target diseases were higher in people residing inside the chemical parks. Spatial pattern of PTS in soil can be used as an indicator to assess the risks posed by PTS to local people.

This study aimed to investigate the relationships between the occurrence of PTSs in soil and local human health in industrial areas of Northern China. Because of the qualitative attribution of the sociological survey, we could not conclusively determine the specific cause-and-effect relationship between PTS concentrations and the incidences of diseases induced by PTS. Further studies with advanced biostatistical methods would be needed to assess the relationships. However, this preliminary attempt to relate PTS and disease outcomes can provide information for future studies. In other words, it is also an exploration of a new approach - combining a sociological survey with PTS levels in an area to establish the association between the soil contamination and human health. This study will help develop methods for assessing risks from soil contamination and diseases clusters in a region.

\section{Acknowledgment}

This work was supported by the National Basic Research Program (973) of China (No. 2007CB407307), the External Cooperation Program of the Chinese Academy of Sciences (No. GJHZ0910, GJHZ0948), and the State Key Laboratory Project (No. SKLURE2008-1-4). We are grateful to Prof. K. Kannan, from Wadsworth Center, New York State Department of Health and State University of New York, School of Public Health, for comments and improvement of the content and languages to the manuscript.

\section{References}

Abrahams P W, 2002. Soils: their implications to human health. The Science of the Total Environment, 291(1-3): 1-32.

An Q, Dong Y H, Wang H, Ge C J, 2005. Residues and distribution character of organochlorine pesticides in soils in Nanjing area. Acta Scientiae Circumstantiae, 25(4): 470474.

Cai Q, Mo C, Wu Q, Katsoyiannis A, Zeng Q, 2008. The status of soil contamination by semivolatile organic chemicals (SVOCs) in China: A review. Science of the Total Environment, 389(2-3): 209-224.

Chung M K, Hu R, Cheung K C, Wong M H, 2007. Pollutants in Hong Kong soils: Polycyclic aromatic hydrocarbons. Chemosphere, 67(3): 464-473.

Cocco P, Fadda D, Billai B, D’ Atri M, Melis M, Blair A, 2005. Cancer mortality among men occupationally exposed to dichlorodiphenyltrichloroethane. Cancer Research, 65(20): 9588-9594.

Destefani E, Kogevinas M, Boffetta P, Ronco A, Mendilaharsu M, 1996. Occupation and the risk of lung cancer in Uruguay. Scandinavian Journal of Work Environment and Health, 22(5): 346-352.

Dewailly É, Ayotte P, Bruneau S, Gingras S, Belles-Isles M, Roy R, 2006. Susceptibility to infections and immune status in inuit infants exposed to organochlorines. Environmental Health Perspectives, 108: 205 -211.

Falandysz J, Brudnowska B, Kawano M, Wakimoto T, 2001. Polychlorinated biphenyls and organochlorine pesticides in soils from the southern part of Poland. Archives of Environmental Contamination and Toxicology, 40: 173178.

Ge C J, An Q, Dong Y H, Yu H M, 2006. Distribution of organic pollutions in agricultural soil in Nanjing City. Resources and Environment in the Yangtze Basin, 3: 362-364.

Ge X L, Jiao X C, Yuan X, Li Q, 2008. Environmental geochemical migration of polycyclic aromatic hydrocarbons in Xuzhou urban area. Rock and Mineral Analysis, 27(6): 409412.

Gelboin H V, Paul O P T, 1979. Polycyclic Hydrocarbons and Cancer. Academic Press, New York. 189-202.

Gerber C, von Hochstetterm A R, Schuler G, Hofmann V, Rosenthal C, 1995. Penis carcinoma in a young chimney sweep. Case report 200 years following the description of the first occupational disease. Schweiz Med Wochenschr, 125(24): 1201-1205.

Gong Z, Wang G, Xue J, Li B G, 2003a. The residues distribution of DDT and its metabolites in soils from Tianjin Region, China. Acta Scientiae Circumstantiae, 23(3): 311-314. 
Gong Z M, Cao J, Li B G, Xu F L, Tao S, 2003b. Residues and distribution characters of $\mathrm{HCH}$ in soils of Tianjin area. China Environmental Science, 23(4): 447-451.

Hao R, Peng S L, Song Y T, Yang G Y, Wan H F, 2004. Distribution of priority polycyclic aromatic hydrocarbons in soils in Shantou Specific Economic Zone. Ecology and Environment, 13(3): 323-326.

Hemminki K, Pershagen G, 1994. Cancer risk of air pollution: epidemiological evidence. Environmental Health Perspectives, 102: 187-192.

Hu J, Wan Y, Shao B, Jin X, An W, Jin F et al., 2005. Occurrence of trace organic contaminants in Bohai Bay and its adjacent Nanpaiwu River, North China. Marine Chemistry, 95(1-2): $1-13$.

Hu J, Zhang G, Liu C, 2006. Pilot study of polycyclic aromatic hydrocarbons in surface soils of Guiyang City, People's Republic of China. Bulletin of Environmental Contamination and Toxicology, 76: 80-89.

Husain N, Gater R, Tomenson B, Creed F, 2006. Comparison of the personal health questionnaire and the self reporting questionnaire in rural Pakistan. Journal Pakistan Medical Association, 56(8): 366-370.

IARC, 1987. IARC monographs on the evaluation of carcinogenic risks to humans, suppl. 7, Overall Evaluations of Carcinogenicity: An Updating of IARC Monographs 1-42. IARC, Lyon, France.

Jane H, Chris C, Richard W, 2000. MOMs and POPs. Environmental Working Group, Washington DC.

Jin S W, Li M, Liao T, Hui Y, Xu Y, 2009. Residue analysis of organochlorine pesticides in soil from Wuhan rural. Journal of Wuhan Institute of Technology, 31(7): 1-3, 22.

Kannan K, Tanabe S, Giesy J P, Tatsukawa R, 1997. Orgaochlorine pesticides and polychlorinated biphenyls in foodstuffs from Asian and Oceanic countries. Reviews of Environmental Contamination and Toxicology, 152: 1-55.

Li X, Ma L, Liu X, Fu S, Cheng H, Xu X, 2006. Polycyclic aromatic hydrocarbon in urban soil from Beijing, China. Journal of Environmental Sciences, 18(5): 944-950.

Li J, Lu L Y, Jiao W T, Wang T Y, Shi Y J, Luo W, 2008a. Concentration and origin of polycyclic aromatic hydrocarbons in surface soil in an industrial area of Tianjin, China. Journal of Environmental Sciences, 18(10): 2111-2117.

Li J J, Chen J W, Liu C, Yang Z F, 2008b. Investigation and evaluation of DDT residues in soils in the suburbs of Beijing, China. Geological Bulletin of China, 27(2): 252256.

Liao Y J, 2009. Preliminary study on polycyclic aromatic hydrocarbon (PAHs) in soil of special region in Guangzhou. Environment and Ecology in the Three Gorges, 2(4): 13-15.

Liu W X, Li Y, Zuo Q, Liu S Z, Tao S, 2008a. Residual characteristics of $\mathrm{HCHs}$ and DDTs in surface soils from the western zone of Bohai Bay. Acts Seiemiae Circumatamiae, 1: $142-149$.

Liu C, Chen J W, Yang Z F, Tao Y, 2008b. The investigation and evaluation of $\mathrm{HCH}$ residues in soils of Beijing suburbs. Geophysical and Geochemical Exploration, 32(5): 567570.

Lin J Y, Wan W, Zhang J J, 2009. Residual DDTs and their potential ecological risk in soils under different land use in hilly-plain transitional zone. Acta Pedologica Sinica, 4: 736-740.

Lu M, Yuan D, Ouyang T, Lin Q M, 2008. Source analysis and health risk assessment of polycyclic aromatic hydrocarbons in the topsoil of Xiamen Island. Journal of Xiamen Univer- sity, 47(3): 451-456.

Ma X X, Ran Y, 2009. The research for organochlorine pesticides in soils of the Pearl River Delta. Ecology and Environmental Sciences, 18(1): 134-137.

Maliszewska-kordybach B, 1996. Polycyclic aromatic hydrocarbons in agricultural soils in Poland: preliminary proposals for criteria to evaluate the level of soil contamination. Applied Geochemistry, 11(1-2): 121-127.

Manz M, Wenzel K D, Dietze U, Schuurmann G, 2001. Persistent organic pollutants in agricultural soils of central Germany. The Science of the Total Environment, 277(1-3): 187-198.

Mielke H W, Wang G D, Gonzales C R, Powell E T, Le B, Quach $\mathrm{V} \mathrm{N}, 2004$. PAHs and metals in the soils of inner-city and suburban New Orleans, Louisiana, USA. Environmental Toxicology and Pharmacology, 18(3): 243-247.

Motelay-Massei A, Ollivon D, Garban B, Teil M J, Blanchard M, Chevreuil M, 2004. Distribution and spatial trends of PAHs and PCBs in soils in the Seine River basin, France. Chemosphere, 55(4): 555-565.

Mumford J L, Li X M, Hu F D, Lu X B, Chuang J C, 1995. Human exposure and dosimetry of polycyclic aromatic hydrocarbons in urine from Xuan Wei, China with high lung cancer mortality associated with exposure to unvented coal smoke. Carcinogenesis, 16(12): 3031-3036.

Nadal M, Schuhmacher M, Domingo J L, 2004. Levels of PAHs in soil and vegetation samples from Tarragona County, Spain. Environmental Pollution, 132(1): 1-11.

Pang X G, Zhang F, Wang H J, Hu X P, Zeng X D, 2009. Residual of organochlodne pesticides and distribution features of soils in the southwest area of Shandong Province, China. Geological Bulletin of China, 28(5): 667-670.

Scazufca M, Menezes P R, Vallada H, Araya R, 2009. Validity of the self reporting questionnaire -20 in epidemiological studies with older adults. Social Psychiatry and Psychiatric Epidemiology, 44(3): 247-254.

Shen F, Zhu L Z, 2007. Concentration and distribution of PAHs in vegetables grown near and iron and steel industrial area. Environmental Science, 28(3): 669-672.

Smith J L, Lee K, 2003. Soil as a source of dust and implications for human health. Advances in Agronomy, 80: 1-32.

Sun X J, Shi C, Xu S Y, Pan F F, Wang P H, Ma J L et al., 2008. Concentration and sources of polycyclic aromatic hydrocarbons in surface soil of north suburban Shanghai, China. Research of Environmental Sciences, 21(4): 140144.

Tao S, Yang Y, Cao H Y, Liu W X, Coveney R M, Xu F L, 2006. Modeling the dynamic changes in concentrations of gamma-hexachlorocyclohexane (gamma-HCH) in Tianjin region from 1953 to 2020. Environmental Pollution, 139(1): 183-193.

Turusov V, Rakitsky V, Tomatis L, 2002. Dichlorodiphenyltrichloroethane (DDT): Ubiquity, persistence, and risks. Environmental Health Perspectives, 110(2): 125-128.

US EPA, 2002. Supplemental guidance for developing soil screening levels for superfund sites. OSWER, 9355.4-24.

Wang G, Lu Y L, Wang T Y, Zhang X, Han J Y, Luo W, 2009. Factors influencing the spatial distribution of organochlorine pesticides in soils surrounding chemical industrial parks. Journal of Environment Quality, 38(1): 180-187.

Wang T Y, Lu Y L, Zhang H, Shi Y J, 2005. Contamination of persistent organic pollutants (POPs) and relevant management in China. Environmental International, 31(6): 813-821.

Wang Z, Chen J W, Yang P, Qiao X L, Tian F, 2007. Polycyclic 
aromatic hydrocarbons in Dalian soils: distribution and toxicity assessment. Journal of Environmental Monitoring, 9(2): 199-204.

Wong H L, Giesy J P, Lam P K S, 2006. Organochlorine insecticides in mudflats of Hong Kong, China. Archives of Environmental Contamination and Toxicology, 50(2): 153165.

Xiao C Y, Tai C, Zhao T Q, Wu L, Xu H S, 2008. Distribution characteristics of polycyclic aromatic hydrocarbons in the soil around the Jiaozuo power plant. Acta Scientiae Circumstantiae, 28(8): 1579-1585.

Zhang H Y, Gao R T, Jiang S R, Huang Y F, 2006a. Spatial variability of organochlorine pesticides (DDTs and $\mathrm{HCHs}$ ) in surface soils of farmland in Beijing, China. Scientia Agricultura Sinica, 39(7): 1403-1410.
Zhang H B, Luo Y M, Zhao Q G, Wong M H, Zhang G L, 2006b. Residues of organochlorine pesticides in Hong Kong soils. Chemosphere, 63(4): 633-641.

Zhang K, Qi S H, Xing X L, Zhang Y, Yang D, 2009. Levels and distribution of HCHs and DDTs in soils from Chengdu economic zone. Environmental Science and Technology, 32(5): 66-70, 78.

Zhao B Z, Zhang J B, Zhou L Y, Zhu A N, Xia M, Lu X, 2005. Residues of $\mathrm{HCH}$ and DDT in typical agricultural soils of Huang-Huai-Hai Plain, China. I. Residues in surface soils and their isomeric composition. Acta Pedologica Sinica, 42: 761-768.

Zhou X Y, Cui Z J, 2009. Residues and distributions of $\mathrm{HCH}$ and DDT in orchard soil and apple trees. Environmental Science and Technology, 32(5): 62-65. 